\title{
EDITORIAL
}

\section{Introduction to the First Issue of East Africa Science: Search, Discover, Develop}

\author{
Fabian M. Mashauri, ${ }^{a}$ Harriet Nabudere ${ }^{b}$ \\ aPrincipal Health Officer, East African Health Research Commission, Bujumbura, Burundi; \\ bDeputy Director General, Uganda National Health Research Organisation, Kampala, Uganda \\ Correspondence to Fabian M. Mashauri (fmashauri@eahealth.org)
}

O

$\mathrm{n}$ behalf of the East African Health Commission (EAHRC), we are delighted to share the inaugural issue of East Africa Science (EASci) with our readers. We would like to take this opportunity to acknowledge all of the contributions from authors, reviewers, and the editorial team that have made this first issue possible.

$E A S C i$ is a no-fee, open access, peer-reviewed journal published by the EAHRC of the East African Community (EAC, www.eac.int). The journal will publish papers on a wide range of topics relevant to basic science, technology, and innovation in health. The aims are to contribute to knowledge dissemination, continuing professional development of researchers in the region, and play a part in the mentoring of young, up-and-coming scientists. EASci is the sister journal of the East African Health Research Journal (EAHRJ), which is dedicated to articles informing health policy and practice.

EASci will not only promote research in the basic sciences but also the application of science, technology and innovation (STI) as well as information and communication technology (ICT) in health. This will include clinical trials on investigational pharmaceutical products, devices, and diagnostics, as well as featuring the application of health technologies and solutions, among other related matters. Issues of the journal will include peer-reviewed articles, original articles, reviews, short communications, surveys, commentaries, opinions, book reviews, supplementary issues, essays, and reports related to the advancement in health and medical sciences.

$E A S c i$ is open access with no article processing charges. The journal will initially be published once annually but will eventually build up to 2 issues per year. EASci will be available online at www.eahealth.org and in hard copy. Hard copies will be distributed to all relevant stakeholders, such as government institutions, research institutions, academic institutions, and relevant civil society organisations.

EASci, among other things, aims to:

- Present East African innovations in the health sector

- Provide solutions through research, discovery, and development to priority issues that are relevant to the East African region

- Be a catalyst for innovation and the use of science and technology, including digital health technologies and solutions

- Guide the development of products in health that harness the advancement of science and technology

- Be a forum for sharing innovations and knowledge related to heath

- Provide an avenue for closing the 'knowledge gap' in research and development in health that exists between developing and developed countries

- Enable scholarly recognition of professionals and institutions

- Support the career development of professionals

- Provide a forum for researchers from the EAC to become more visible globally

- Provide direction in setting up health research priorities in the region

- Contribute to economic and social development through research, innovation, and development in health 
We are publishing the inaugural issue of the journal in conjunction with the $7^{\text {th }}$ East African Health and Scientific Conference (EAHSC), taking place in Dar es Salaam, the United Republic of Tanzania, from 27 to 29 March 2019. The main theme of the conference is 'Technology for Health Systems Transformation and Attainment of the UN Sustainable Development Goals'. The conference participants will have the opportunity to discuss the 5 subthemes:

1. Technologies Supporting Data for Health System Decision-making

2. Technologies for Disease Surveillance, Disease Outbreak Detection and Response, and Cross-border Mobility and Disease tracking

3. Innovative Technologies and Solutions for Application in, and Improvement of, Health-Care Service Delivery and Health Outcomes

4. Costing and Financing Health: The Role of Digital Health, International Remittances, Universal Health Care, and EAC Status on the UN SDGs

5. Health Knowledge Management Through Digital Technologies and Solutions in East Africa: Health Research, Training, and Care

As digital health technologies are increasingly being used in health care to improve health services and delivery, the EAHRC management thought that it was imperative to propose to the $14^{\text {th }}$ EAC Sectoral Council of Ministers of Health that the main theme of the $7^{\text {th }}$ EAHSC to be in line with digital health technology. The Sectoral Council of Ministers of Health, having granted their approval, will allow for the consideration of recommendations and strategies on how to harness the potential of digital health technologies to transform the health sector in the East African region. The EAHRC will also launch the Digital Regional East Africa Community
Health (Digital REACH) Initiative during the $7^{\text {th }}$ EAHSC. The Digital REACH Initiative is a new, groundbreaking initiative within the EAC that will implement ICT across all dimensions of the health sector in East Africa. This has the potential to transform health outcomes across the region for millions of people.

The Digital REACH Initiative will be implemented through its 10-year strategic plan (2019-2028). The strategic plan presents a common regional vision and strategic approach for regional collaboration in health. It also serves as a platform for development partner and private sector input to support coordination and shared investment. The plan allows the EAC to pursue the funding necessary to scale-up operations.

The EAC is the first African Union Regional Economic Community to create an ambitious and coordinated approach to digital health, which is prioritised for investment by all presidents of its partner states. The successful implementation of the Digital REACH Initiative will fully support the EAC's integration of the agenda, "One people, One Health System".

In addition to this first issue of EASci, the EAHRC will also launch 2 supplementary issues, EASci volume 1 supplement 1, 2019, and EAHRJ volume 1 supplement 1, 2019. These 2 supplementary issues will publish the abstracts submitted for presentation at the $7^{\text {th }}$ EAHSC.

Competing Interests: None declared.

Cite this article as: Mashauri FM, Nabudere $\mathrm{H}$. Introduction to the First Issue of the Journal of East Africa Science: Search, Discover, Develop. E Afr Sci. 2019;1(1):1-2. https://doi.org/10.24248/EASci-S-19-00007.

(C) Mashauri and Nabudere. This is an open-access article distributed under the terms of the Creative Commons Attribution License, which permits unrestricted use, distribution, and reproduction in any medium, provided the original author and source are properly cited. To view a copy of the license, visit http://creativecommons.org/ licenses/by/4.0/. When linking to this article, please use the following permanent link: https://doi.org/10.24248/EASci-S-19-00007. 